\title{
Diálogo entre Zubiri y Lacan: la poderosidad de lo real y la angustia
}

\section{Dialogue between Zubiri and Lacan: the powerfulness of the real and the anguish}

\author{
Antonio Sánchez Antillón \\ Instituto Tecnológico de Estudios Superiores de Occidente (MÉXICO) \\ CE: antonios@iteso.mx ID ORCID: 0000-0002-4781-2669
}

DOI: $10.32870 /$ sincronia.axxiii.n76.10b19

(C) $\mathrm{BY} \cdot \mathrm{NC}$

Esta obra está bajo una Licencia Creative Commons Atribución-NoComercial 4.0 Internacional

Recibido: $26 / 03 / 2019$

Revisado: 02/04/2019

Aprobado: 16/05/2019

\section{RESUMEN}

Inicialmente se presentan antecedentes del problema del lenguaje y el ente en la filosofía y, del lenguaje en el psicoanálisis. Después describe coincidencias y diferencias entre Zubiri y Lacan y explica cómo Heidegger es punto común en sus reflexiones. Al elaborarlo se encontró divergencias que impiden una igualación pero que permiten la comprensión de un autor respecto al otro; un concepto en Zubiri puede ser clave para comprender lo real lacaniano: poderosidad. En Zubiri, lo radical es la poderosidad como atributo de la fuerza y poderío de lo real que en su formalidad imprime un afecto en alteridad al percipiente. En Lacan y Heidegger, esa primera impresión suscita angustia por la condición a-simbólica propia del encuentro prístino entre el percipiente y la exterioridad. Poderosidad-angustia servirán para hacer dialogar los linderos de lo real, pensado desde algunos textos de Zubiri y de Lacan. Finalmente se concluye, a Zubiri y Lacan cuatro letras los unen y separan: $r$-e-a-I. 
Palabras clave: Actualidad. Angustia. De suyo. Real. Realidad. Transcendentalidad.

\begin{abstract}
:
Initially, a background of the problem of language and entity in philosophy and of language in psychoanalysis is presented. This article describes coincidences and differences between Zubiri and Lacan, and explains how Heidegger is a common point in his reflections. When elaborating it, divergences that prevent an equalization but that allow the understanding of one author with respect to the other were found; a concept in Zubiri can be key to understanding the real Lacanian: powerfulness. In Zubiri, the radical is the powerfulness as an attribute of the strength and power of the real that in its formality prints an affection in otherness to the percipient. In Lacan and Heidegger, that first impression provokes anguish by the a-symbolic condition of the pristine encounter between the percipient and the exteriority. Powerfulness-anguish will serve to make dialogue the boundaries of the real, thought of in some texts by Zubiri and Lacan. Finally, it is concluded: to Zubiri and Lacan four letters unite and separate them: r-e-a-I.
\end{abstract}

Keywords: Actuality. Anguish. In his own right. Transcendentality. Real. Reality.

\title{
Introducción
}

“El objeto del deseo no puede ser concebido a la manera con la que se nos enseña que no es ningún noema, ningún pensamiento de algo que se haya vuelto hacia algo -único punto alrededor del cual puede volver a encontrar, el idealismo, su camino hacia lo real"

(Lacan, 1963, pág. 3).

"Nos enseñan, en efecto, que no hay ninguna noesis, ningún pensamiento, que no se dirija a algo. Es el único punto, parece, que le permite al idealismo reencontrar su camino hacia lo real. Pero el objeto del deseo, ¿puede ser concebido de esta forma?"

(Lacan, 2006b, pág. 114). 


\section{Límites}

Las dos citas anteriores provienen de editores diferentes del mismo Seminario, la discrepancia es fundamental: noesis y noema están vinculados -en la fenomenología- pero de ninguna manera son lo mismo. Este ejemplo ya muestra la dificultad intrínseca del tema.

Este artículo explica algunos puntos comunes entre filosofía y psicoanálisis, así como entre Zubiri y Lacan. Para ello se hace un pequeño recorrido de la relevancia de pensar el Ser y el ente en la filosofía, y se comparan algunos conceptos comunes entre el filósofo y el analista. Es admisible forzar el diálogo entre la filosofía y el psicoanálisis porque ambos no sólo se sirven del lenguaje, sino son sus servidores al momento de pensar lo real del Ser en el mundo. En la primera parte -espejos planos- se busca entender a cada autor desde sí mismo para comprender qué entendieron por real. En la segunda -espejos cóncavos- se lee a cada autor desde la óptica del otro, justo como se observa el reflejo de un espejo en otro; este ejercicio tiene la intención de plantear cómo una teoría puede ayudar a la comprensión de la otra. Al final se ofrecen algunas conclusiones que permiten diferenciar la postura de los dos autores respecto a la fuerza de imposición y la poderosidad ${ }^{1}$ de lo real.

En cuanto a las fuentes, en la contextualización del problema sobre el uso del lenguaje en la filosofía y el psicoanálisis se alude a varios autores. Para el desarrollo nuclear del trabajo se retoma de Zubiri la trilogía de Inteligencia sentiente, su texto Sobre la esencia y un póstumo, Sobre el sentimiento y la volición; se cita sólo un artículo, de Diego Gracia ${ }^{2}$. En cuanto a Lacan se limita a tres Seminarios, Los escritos técnicos de Freud, Las psicosis y, La angustia; además, dos conferencias, una de 1953, El simbólico, el imaginario y el real, otra de 1974, La tercera.

\footnotetext{
${ }^{1}$ Zubiri utiliza el concepto de poderosidad para aludir al animismo y para hablar de lo real utiliza el concepto de transcendentalidad y lo vincula al arkhé de Anaximandro. Sólo por cuestión de legibilidad el autor del artículo utiliza el concepto de poderosidad para hablar de la formalidad de realidad, pero no hay que olvidar que Zubiri dice transcendentalidad.

${ }^{2}$ Se aclara que cuando es necesario remitir a conceptos claves se hace uso de otras obras donde hace esas definiciones, ya que en los textos analizados los supone conocidos, es el caso del concepto de respectividad.
} 


\section{Planteamiento del problema}

\section{La filosofía}

La filosofía tiene como base el lenguaje y su uso: pensar. Si bien al pensar notamos que es difícil, confía el filósofo en el lenguaje y su uso. Algunos filósofos no dudan en la transparencia del lenguaje y de sus posibilidades mientras que otros saben y evidencian su plasticidad y su capacidad de deslizar el campo del sentido; por lo que podríamos apostar que el lenguaje es para el hombre el piso en "la casa del jabonero". Escribir puede ser complejo, pero con esmero se pueden acomodar las palabras para, más o menos, expresar lo que se quiere. Si bien podemos suponer este principio como cierto, es importante advertir que hay una diversidad de posiciones filosóficas sobre la diada logos-mens así como sobre el uso de la palabra. Por lo que estos temas no son un problema nuevo en la historia de la filosofía, sino el campo propio en la construcción del saber; el quid del Ser no es sin logos, así lo testifica el mismo mito de la creación. El lenguaje es constitutivo y constituyente del ente, en tanto ser hablante.

La filosofía desde el tiempo de los clásicos griegos discute el papel del logos en la práctica del vivir humano. Zubiri (1987) en su escrito "Sócrates y la sabiduría griega" hace todo un recuento, en el horizonte de pensamiento griego, de dos conceptos fundamentales: logos y noûs. Estos dos atributos los comparte el humano con los dioses de acuerdo a los mitos y la teorización de los filósofos griegos. Es gracias a esos dos elementos que el filósofo puede inquirir: ¿qué es el Ser en cuanto Ser? y ¿qué es el ser de las cosas?

Para el horizonte de pensamiento griego, el hombre es parte de la naturaleza, por lo que tiene ciertas coincidencias y diferencias. No sólo es un ser vivo, sino un ergón, alguien que se realiza haciéndo-se con las cosas (Pragmata). Estos atributos en el mito de Prometeo fueron robados a los dioses y entregados al humano. Logos y mente (inteligencia: luz interior) son cejillas de la bisagra propia del existir humano; el logos no expresa sino lo que la mens piensa y descubre (Zubiri, 1987). En ese recorrido Zubiri va mostrando las diferencias de sentido que tiene el logos en Heráclito, Parménides, Aristóteles y Platón entre otros. 
De acuerdo con lo desarrollado por Zubiri (1987), podemos partir del supuesto griego: sin logos no hay posibilidad de discurrir el qué del mundo, ni el qué del hombre. Dado que el hombre es naturaleza ( $\phi u ́ \sigma \eta)$, la polis es una expresión del habitar humano, es parte de la naturaleza, un don compartido con lo divino. El ordo de la naturaleza es la primera fuerza de imposición, imperativo al cual el hombre debe atenerse para poder enfrentar el caos. Zubiri (1987), recuerda en ese escrito que en la mítica griega hay tres elementos propios de la forzosidad de la naturaleza contra las cuales ni el mismo Zeus puede, estas son las moiras. Aristóteles (1994) en la Metafísica, agrega en contra del atomismo, que el azar y la espontaneidad no son causas primeras sino accidentales en tanto que dependen del pensamiento (el agente que intelige) y la naturaleza.

En el horizonte griego según Zubiri, no hay separación entre el ser que intelige y lo inteligido en tanto que en el centro está el Ser mismo, la naturaleza. El nous puede ser considerado como luz interna o como la visión que escruta lo real en tanto exterioridad patente, pero también como pensar de ese despliegue de la naturaleza en su precariedad y lo inconmovible. Es por el nous (en cuanto inteligir) que es posible que se puede dar cuenta de la naturaleza (primera constatación del Ser, ES, Parménides); su verdad arranca en la expresión prístina del logos en tanto Aletheía que señala el existente ahí, la naturaleza que produce cosas de suyo (Anaximandro), que se impone por la fuerza de ser como de no ser (Parménides-Heráclito), así como cuando el hombre interroga esa físis con pretensiones de universalidad; el saber del ser de las cosas o del Ser en tanto Ser. Desde aquí la mens está en el inicio, en el proceso y en el encuentro de la verdad que enjuiciamos sobre el ser de las cosas; llegar a la última razón de ellas es propio del quehacer teorético.

El recorrido que hace Zubiri (1987), se puede considerar en correlato o intertextualidad con el "Ser y el tiempo" de Heidegger; éste último precisa que el logos, entendido como el decir, tiene al

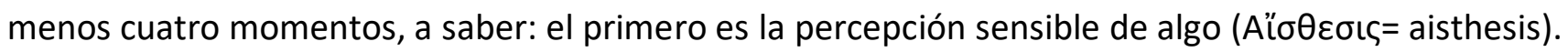
No se trata en esto de determinar lo verdadero o falso sino de un ver inteligente el cual puede ser suficiente o insuficiente. El segundo es aletheía, expresión que determina entre lo cierto y no cierto; el tercero, es el logos en tanto razón, como la intelección misma de la cosa, y finalmente, el logos 


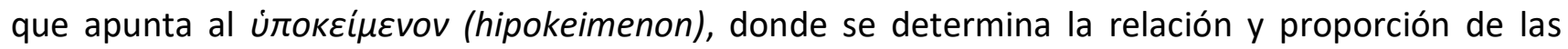
cosas.

Lo que podríamos rescatar en lo desarrollado hasta aquí es que el campo de lo real en los griegos, está dado por la naturaleza y por quien la aprehende, en tanto que es a partir de ese estar colegido por ella que el sujeto puede verbalizar algo.

La pregunta fundamental de este trabajo, teniendo en cuanta las ideas expuestas sobre el pensamiento griego, es ¿cómo se posicionan y responden Lacan y Zubiri al tema de lo real, con su atributo de fuerza y poder? Seguramente para quienes conocen algunas de las propuestas de estos autores ya vislumbran ciertas hipótesis. Para poder precisar mejor el diálogo entre los inéditos de estos autores y las problematizaciones antiguas hay que aclarar que algunos fenomenólogos rescatan el problema del ser superando el dualismo o naturalismo de Descartes y Espinoza, respectivamente.

Las coordenadas que usan Heidegger, Sartre y Merleau-Ponty son de estirpe griego y con una gran influencia de Nietzsche. Nietzsche (1990), en contra de la aspiración moderna positivista refiere que aquello que el investigador puede verbalizar de la naturaleza son metáforas y metonimias antropomorfizadas. Por lo que, "No hay unidades últimas inmutables, ni átomos, ni mónadas; también aquí el 'ser' fue precisamente introducido por nosotros (por razones prácticas, útiles, de perspectiva" (Nietzsche, 2000, p. 479). La transvaloración nietzscheana no sólo es la caída del horizonte cristiano y su propuesta de valores sino además una apertura epistémica en donde la voluntad de poder se afirma. Voluntad de poder que dentro de sus diversas acepciones puede identificarse como impulso primario de todo organismo vivo, no sólo de pervivir sino de hacerse el más fuerte, de ahí que el binomio placer y displacer no es lo prístino del humano, ya que en ello ya hay una aspiración de utilidad. Esta Voluntad de poder pensada como expresión humana tiene su radical aspiración en la construcción de sentido (Nietzsche, 2000; p. 582). Así pues, para Nietzsche el Ser es un concepto generalizador de lo que es la vida (respirar, estar animado, querer, efectuar, devenir). La representación preñada de sentido es el vivir y la esencia más íntima de ese ser es la voluntad de afirmación, de pervivir, de ser el más fuerte, de poder y de imponerse en el mundo. 
Heidegger (1993) teoriza ya no sólo siguiendo las coordenadas griegas del Ser de la naturaleza, sino en tanto realidad humana, ser ahí (Dasein) en el mundo. Y explícitamente Sartre (2006), reconoce que la esencia del Ser en tanto realidad humana es el sentido. Merleau-Ponty afirma también que "por estar en el mundo estamos condenados al sentido; y no podemos hacer nada, no podemos decir nada que no tome un nombre en la historia" (Merleau-Ponty, 1994; p. 22). Este campo de sentido no es primero pensamiento sino mundo vivido, cuerpo vivido con otros. Bajo este principio que rompe el registro de la voluntad de verdad y la pretensión de causas últimas; reconoce por tanto, que el método de la reducción fenomenológica a lo que accede es:

(...) al sentido que se transparenta en la intersección de mis experiencias y en la intersección de mis experiencias con las del otro, por el engranaje de unas con otras; es inseparable, pues, de la subjetividad e intersubjetividad que constituyen su unidad en la reasunción de las experiencias. (Merleau-Ponty, 1994; p.19).

De frente a estas posiciones podemos inferir cierta intertextualidad de Lacan con los fenomenólogos, al tratar estos mismos temas y respondiendo de distinta manera, ya que desde sus primeras enseñanzas pondera que la experiencia vivida pende de la función y campo de la palabra. La experiencia vivida no es diáfana sino una narración entre un hablante y un escucha, gracias a que ambos comparten cierto código lingüístico, y aún la interpretación del sueño, pende de la retórica por el intercambio del dispositivo analítico.

\section{El psicoanálisis}

Para el psicoanalista las palabras son arcilla, pero en otra versión porque no trabaja sólo con las palabras que el analizante piensa y ofrece sino con las que el paciente expresa sin querer o haciendo fallar el sentido por intercambios en equívocos o entredichos. Se trata de precipitar 
intencionadamente en la polisemia y la fractura del habla, confiando en efecto que el hablante hará algo con esto ${ }^{3}$.

Entre el discurso del filósofo y el psicoanalista hay una diferencia, éste último por su práctica usa las palabras que al paciente se le escapan y que sólo atina a expresar, no lo quise decir. Ahí donde el filósofo sólo ve un error en el decir, el psicoanalista despliega una técnica que disuelve la intencionalidad consciente del sujeto. El psicoanalista conjetura en ese "no", la emergencia del sujeto; en tanto frase indicial que apunta a ciertas censuras deseosas acalladas por las inhibiciones o prohibiciones impuestas por el Otro en tanto discurso social. El analista sí trabaja con el lenguaje, pero no el lenguaje bajo el régimen imperativo de decir-lo "objetivo" sino con la perspectiva del "juego del lenguaje" emergente en el ejercicio pragmático del habla; un apalabra-miento (en este doble sentido a la vez que se expresa se oculta el sentido) gestado desde una "la lengua" particular del hablante (se habla desde un en sí para sí, dice el fenomenólogo). El lenguaje no es transparente porque el habla no atrapa la cosa, ni hay correspondencia entre la materialidad vocal y el objeto que se índica (la relación que se da es arbitraria, por el arbitrio consensuado de la ley que imprime el lenguaje), además de que hay una escisión intra-subjetiva e intersubjetiva. La primera se evidencia porque el sujeto del enunciado no coincide con el sujeto de la enunciación; la segunda tiene que ver con que quien enuncia y quien escucha están posicionados de manera divergente; el que habla como el que escucha lo hace desde distinta constelación lingüística. Hay que decir que este saber de la lingüística es el campo de posibilidad sobre el cual se despliega el juego del lenguaje propio del quehacer analítico.

El diálogo entre el filósofo y el analista puede parecer una charla sin sentido y en ocasiones así ha sucedido; filosofía y psicoanálisis se han disputado terrenos semejantes y más que llegar a un arreglo, se mantienen ciertas divergencias y la extrañeza de uno frente al otro. Quizá por afirmarse en el narcisismo de las pequeñas diferencias. Sin embargo, existe un tema común entre ambas disciplinas: el lenguaje. Algunos filósofos utilizan las palabras de manera "voluntaria-consciente"

\footnotetext{
${ }^{3}$ Lacan dirá en Función y Campo de la Palabra que, el inconsciente, es aquella parte del discurso concreto en cuanto transindividual que falta a la disposición del sujeto para restablecer la continuidad de su discurso consciente.
} 
(con voluntad de afirmación), el psicoanalista utiliza las palabras a modo de los antifilósofos como Nietzsche, sabiendo que los intercambios lenguajeros están en la construcción y desplazamiento de sentidos, mediados por metáforas y metonimias. Ambos saberes, tienen como uno de sus objetos de estudio el lenguaje, pero al mismo tiempo las utilizan como su herramienta de trabajo. Justo desde esta base común, es que se pueden indagar temas que pueden fertilizar ambos campos; tanto Zubiri como Lacan hablan del lenguaje y la relación de éste con lo real y la realidad de sentido.

\section{El contexto}

Franz Brentano, describió la conciencia como un correlato entre dos instancias, una como acto del ser humano y otra que es intencional; estas aportaciones son elaboradas y puestas en circulación por un pensador, Husserl, quien es un antecedente en la construcción del pensamiento de Heidegger, Sartre, Merleau-Ponty y Zubiri, y los fenomenólogos son referente dialógico para Lacan. Zubiri y Lacan son contemporáneos, tienen acontecimientos y antecedentes dialógicos comunes.

\section{Espejos planos}

En este apartado se habla de algunos conceptos claves en Zubiri los cuales permitirán comprender el concepto que servirá para vincularlo con Lacan, el de poderosidad. Más adelante se habla de lo difícil que es plantear el concepto de lo real y cómo la lectura desde la angustia puede ser una clave exitosa para su comprensión.

\section{Zubiri}

\section{Presupuesto}

Zubiri creó un vocabulario para explicar su filosofía y una palabra clave en su obra es el de intelección, que la define como actualización de la realidad. Esto le permitió describir lo que denomina aprehensión primordial de realidad y definir un concepto de realidad con un rasgo que la filosofía ha vinculado a la religión: lo poderoso. La aprehensión tiene tres momentos, se abordará 
con mayor detenimiento sólo el primero, el segundo se tocará sólo para contrastar lo que Zubiri llama realidad y cosa sentido.

1. La intelección como el momento noético de la aprehensión humana.

2. La actualización como el momento noemático de la aprehensión humana.

3. La realidad como el momento noérgico de la aprehensión humana.

\section{La intelección como el momento noético de la aprehensión humana: inteligencia sentiente}

Noético está relacionado con noesis y es un concepto utilizado por Zubiri para hablar de la intelección, pero sin considerarla como expresión de una facultad sino como un acto que tiene dos términos: algo que me está presente y el darse cuenta de eso presente. La aprehensión "es un acto en que se ha aprehendido lo que me está presente precisa y formalmente porque me está presente" (Zubiri, 1980, pág. 23).

Zubiri establece su trilogía de inteligencia sentiente frente a la fenomenología y Heidegger sin darle relevancia a la noesis o al noema sino a la actualidad de lo real ante la aprehensión: "El noema y la noesis no son momentos intelectivos primarios. Lo radical es un devenir de 'actualidad"' (Zubiri, 1980, pág. 64).

Como la impresión de la realidad sucede por medio de los sentidos, es sentiente; como presenta algo otro, algo real, es intelectiva. De ahí que la inteligencia para Zubiri sea inteligencia sentiente. Sin embargo, entre la aprehensión del animal y del humano hay una diferencia, "el sentir humano es co-actualización de la realidad; en este "con» de realidad se funda la conciencia humana. El sentir animal es co-estimulidad signitiva" (Zubiri, 1980, pág. 164). Además, sea animal o humano el sentir tiene tres momentos:

1. El momento de suscitación que consiste en la percepción de un estímulo para el animal, y para el humano es la actualización de algo real; este es el momento de la aprehensión, el momento en que lo otro impresiona al sujeto: es impresión de realidad.

2. El momento de modificación tónica, que consiste en que ante la impresión de la realidad el sujeto queda de una manera diferente; el animal simplemente está de una manera 
determinada, el sujeto se siente en la realidad. Es un sentimiento de aquello que lo afecta, la realidad.

3. El momento de la respuesta, que para el animal está en función de su posición en la clase taxonómica, pero para el humano es sólo una tendencia que lo lleva a una elección, es una volición tendente.

Animal y humano comparten los tres momentos, pero se distinguen por el carácter de realidad que conlleva el acto de darse cuenta. El sentir para Zubiri tiene una característica que la filosofía no ha considerado: la impresión de realidad, un rasgo que el animal no posee. Dicha impresión tiene tres momentos constitutivos (Zubiri, 1980, pág. 30):

1. En primer lugar, la afección es el momento en que algo afecta al animal, sea calor, sonido, destellos; el animal padece algo, de ahí es que los griegos calificaron a las impresiones como pathémata (Zubiri, 1980, pág. 32).

2. Enseguida la alteridad, en la cual para el humano algo queda -ante él- con una cierta formalidad, algo está presente como nota.

3. Y en tercer lugar la fuerza de imposición, la cual muestra que la realidad se impone al sujeto.

Como parte del momento de alteridad, el hombre aprehende la realidad como algo de suyo, algo que no hace el animal. La realidad no es signo de respuesta para el humano, es algo más: la realidad es algo que queda, pero un quedar que se impone. La aprehensión primordial de realidad deja al sujeto ante lo real, entendida como el "de suyo" que es además fuerza de imposición y poder que domina todo acto posterior del inteligir humano.

Estos tres atributos de lo real impelen ineludiblemente, el sujeto no puede quedarse simplemente en lo real, para sobrevivir necesita apropiarse de las posibilidades que están a su alcance y para hacerlo necesita saber qué son las cosas, porque sólo así puede saber a qué atenerse. La forma de saber qué es una cosa entre las demás y cómo son las cosas allende la aprehensión es a través del logos y la razón. 


\section{La re-actualización de la realidad: el logos y la razón.}

Como se mencionó, logos y razón son exigidos por el desarrollo de la inteligencia, el sujeto no puede quedarse en la aprehensión primordial de realidad; de quedarse en ella -experimento banal porque no sabemos qué sería eso- el sujeto flotaría en lo real. Sin embargo no sucede, la persona necesita saber a qué atenerse para poder estar en la realidad, lo cual requiere que ella actualice lo real aprehendido entre otras realidades -tarea del logos- (Zubiri, 1982) y lo re-actualice al concebir cómo es esa realidad más allá de su aprehensión -tarea de la razón- (Zubiri, 1983). A continuación, se describirá cómo conceptualiza Zubiri la aprehensión de una realidad entre otras.

\section{La existencia}

La realidad es lo que actúa desde sí mismo, pero también puede haber algo que puede estar, sin ser de suyo; "existir 'realmente' es el modo de existir que consiste en tener existencia 'de suyo'" (Zubiri, 1962, pp. 396-397). Esto significa que puede haber existencias que no son reales, pero no puede haber reales que no existan. El problema en esto es que se puede pensar que para existir se tiene que ser real, pero para Zubiri no es así. Ya que es posible que exista algo para los hombres que no sea real, es el caso de las figuras mitológicas. Son apariencias que existen porque está apoyadas en algo, parece que existen de suyo, pero no tienen la capacidad del हैpyov, de actuar como realidad desde sí mismo. A "esta ambivalencia de la figura aparente pero no real le llama «espectro» de realidad" (Zubiri, 1962, p. 398).

Comenta Diego Gracia que, aunque Zubiri delineó una metafísica del espectro, no llegó a estructurar una noología del mismo, a lo que en Sobre la esencia llamó 'espectro', en Inteligencia y logos le denominó 'aspecto' (Gracia, 2016, p. 98). Ambos conceptos caen en lo que Zubiri denomina re-actualización de lo real, no son, por tanto, aprehensión primordial de realidad. 


\section{La simple aprehensión o la re-actualización de la realidad}

Para Zubiri la «simple aprehensión» prescinde de lo que un contenido aprehendido es en realidad, no prescinde del carácter de realidad. Con la «simple aprehensión» la persona se plantea qué sería una cosa aprehendida entre otras cosas, de manera que "el contenido de estas cosas deja de ser contenido 'de ellas' y queda reducido a ser principio de inteligibilidad de la cosa que remitió a estas otras cosas" (Zubiri, 1982, p. 90).

Zubiri da el ejemplo de ver un bulto entre los árboles, donde estos árboles sirven para saber qué sería ese bulto entre ellos; no se quita el carácter de realidad, no se puede, pero ahora el árbol sirve para saber qué es ese bulto. Se ha quitado el contenido para decir, ese bulto es «esto» entre los árboles, sin saber qué sea ese 'esto'. “Al 'esto' en cuanto mero término de la percepción es a lo que llamaré percepto. Reducir el contenido de la cosa real a percepto: he ahí la primera forma de simple aprehensión" (Zubiri, 1982, p. 97).

Con la acción de concebir un «esto» entre los árboles y nombrarlo (darle contenido), Zubiri hace emerger el primer momento de lo irreal de la aprehensión; en un segundo momento se toman las notas que vienen del percepto y se estructuran "como» algo, eso es un ficto. Con el ficto se finge algo, no la realidad (ella está dada en la aprehensión primordial de realidad) sino cómo sería la cosa en realidad. En un tercer momento, del ficto se puede llegar a pensar qué es esa realidad en la aprehensión, no su carácter de realidad sino qué sería en la realidad; a esto Zubiri le nomina, concepto. Sin el paso por la irrealidad que hacen los perceptos, fictos y conceptos, estaría en la realidad, pero no podría conjeturar qué es esa realidad.

\section{La alucinación y la ilusión}

En el caso de la alucinación y de la ilusión el individuo está frente a algo que existe, pero no es real. La ilusión puede derivarse de causas físicas como el cansancio de la retina o la refracción de la luz, de tal suerte que podemos estar percibiendo una existencia que no es real. Si es una alucinación derivada de la ingestión de una droga o de una patología tendremos la presencia de una existencia, pero al igual que la ilusión, no es real. 
Zubiri (2005) denomina a estos fenómenos, espectros. Es algo que existe y tiene efectos como algo que existe, pero al considerarlo desde el punto de vista de lo real, no lo es porque no tiene la posibilidad de crear un efecto de suyo. La alucinación de comer puede ser tan vívida que no dudamos un punto de su existencia, pero no tendrá ningún efecto real en la nutrición de quien la vive.

\section{La verdad dual}

El que veamos un ser frente a nosotros no significa que sea una ilusión -como ver agua en el pavimento caliente-, aunque puede serlo. Tampoco significa que sea una alucinación -como en un delirio-, aunque puede serlo. Puede ser algo real o algo que para abarcar los dos términos nombraremos, espectro. Podemos estar frente a lo real o frente al espectro.

El espectro es algo que está enfrente, algo que existe, pero cuya existencia no necesariamente implica la realidad, puede existir sin ser real. Como tal, puede tener efectos en la persona, aunque no sean efectos derivados de la realidad sino del espectro. En otro momento al espectro le denominará Zubiri, cosa sentido.

Como se mencionó, existen tres formas en que la realidad se presenta en la forma de «simple aprehensión». Una de ellas es el percepto, otra el ficto y el tercero el concepto. Cada una de ellas nos coloca de una manera diferente ante la realidad, de una manera re-actualizada. Esto es lo que sucede cuando percibimos una ilusión o alucinamos. Algo que está enfrente existe, pero no es de suyo porque no puede actuar como realidad sino como cosa sentido.

\section{La actualización como el momento noemático de la aprehensión humana: la realidad}

Zubiri reflexiona el concepto de realidad frente a la fenomenología, por lo que teorizará lo trascendente como propio de la realidad, en tanto formalidad. Su apuesta es que lo real es en 
respectividad ${ }^{4}$ entre la formalidad de realidad y la impresión primordial de realidad; y entre el "de suyo" y su apertura en "el más" allá de lo contenido.

En la aprehensión queda algo otro como siendo "de suyo", es el momento de alteridad. Es la realidad que queda bajo su primariedad formal; si se percibe una nota o un conglomerado de éstas, que por su estructura aparece como un sistema, es por el carácter primario de lo real en tanto formalidad aprehendida, bajo impresión simple de realidad.

Una cosa tiene un cierto contenido, pero este radica en algo más primario, a saber el modo de quedar como algo en propio, de suyo, es su formalidad, es decir, la "Cosa real es aquella que actúa sobre las demás cosas o sobre sí misma en virtud formalmente de las notas que posee 'de suyo'"' (Zubiri, 1980, p. 60).

Si se percibe una mesa, es algo real en cuanto a las notas que posee (dureza, peso, tamaño etc.) pero no en cuanto mesa; es mesa porque tiene un sentido en mi vida, la he integrado como un útil en mi vida. Pero no es real en cuanto mesa sino en cuanto a las notas que posee de suyo. Esto que parece sencillo tiene una implicación enorme: las cosas actúan sobre las demás no como cosas sentido sino como cosas realidad (en respectividad):

Por esto, los efectos que produce la silla no son reales si se considera la silla qua silla; la silla no actúa sobre las demás cosas qua silla, sino que actúa sobre ellas, por ejemplo, qua madera, o por la forma que posee. Es decir, el carácter érgico presupone la realidad. Y sólo es ह̌pyov aquello que algo produce por lo que realmente es; esto es, por las notas que posee "de suyo". (Zubiri, 1962, p. 402).

${ }^{4}$ Dirá Zubiri (1979, p. 32): “Toda cosa real está constituida en apertura hacia sí misma. Y su constitutiva suidad es justo el resultado radical de la respectividad. Porque, en efecto, en la apertura se está 'abierto-a'. Y por ser el momento de realidad un momento abierto, nada es realidad sino respectivamente a aquello a lo que está abierto. Con lo cual lo real está constituido como realidad, tan sólo por esta respectividad del momento de realidad, y a su vez, su forma y modo de realidad es forma y modo respectivamente a su contenido. La apertura funda la intrínseca y formal suidad, y la suidad es justo el resultado de esta intrínseca y formal respectividad. En apertura es como la realidad constituye lo real como "suyo"; y la constitución misma es, por tanto, respectividad. Ahora vemos cómo la respectividad no es respectividad a otras formas de realidad, sino intrínseca y formalmente suidad. Es respectividad constituyente. La remisión a otras formas de realidad cuando existen, es, en cambio, respectividad remitente. La respectividad remitente se funda en la respectividad constituyente." 


\section{El poder de lo real}

En el apéndice 6 de Inteligencia sentiente (1980, p. 195) Zubiri plantea que la formalidad de realidad tiene tres rasgos que se dan en un mismo acto; del primero se ha hablado, es el tema del "de suyo", el segundo alude a que las cosas sean y obedezcan a una cierta manera de ser. Refiere que el sentido vulgar le ha llamado la fuerza de las cosas, en Grecia se refirió a ella como la Moira o destino y la ciencia moderna como ley. Esta fuerza de imposición de lo real es el carácter trascendental de la apertura. El tercer rasgo es el poder de lo real, donde lo poderoso no proviene de que las cosas tengan en sí un ánima poderosa -es el tema del animismo- sino que la realidad en cualquier nota, excede al contenido, domina sobre éste. Es el momento formal, transcendentalmente de la realidad.

Esta formalidad de realidad en su respectividad queda en el aprehensor de cierta manera, dada la hiperformalización cerebral del hombre. Es decir, la impresión primordial de realidad es de lo real. La impresión queda pues como afección, alteridad y fuerza de imposición del "de suyo", como en propio e independiente del aprehensor.

Así pues, el "De suyo", la fuerza y el poder son tres momentos propios de la formalidad de realidad que Zubiri vincula al arkhé de Anaximandro. Zubiri, asigna el nombre de transcendentalidad a este carácter de las cosas. Y este respectivamente queda como afectación de lo real de lo otro como siendo en propio de la realidad de lo real e independiente del aprehensor.

El de suyo, la fuerza y el poder nos hablan de la poderosidad de la realidad en tanto real lo cual se nos impone de manera primordial-mente por la índole propia de su ergon y dada la naturaleza del aprehensor en tanto animal de realidades.

Siguiendo a Zubiri, se puede aseverar que desde el punto de vista noológico la fuerza de lo real afecta a quien aprehende la realidad (quien queda en impresión afectante), si tal afectación llegara a ser la angustia, ¿'es una posibilidad entre varias o es una posibilidad privilegida entre otras? Para ir desplegando este diálogo queda abierta la pregunta a Zubiri, desde Heidegger y Lacan: ¿La angustia es un signo de estar ante la fuerza y poderío de lo real? 


\section{Lacan}

\section{Presupuesto}

Se parte de algunas concepciones de lo real, la alucinación y la psicosis para plantear que este camino es una vía para pensar lo real lacaniano: a partir de la angustia primera.

\section{Lo real}

Al comentar el caso del hombre de los lobos, cuando el niño alucina con la mutilación de su dedo, Lacan dice que "Existe algo así como un mundo exterior inmediato, manifestaciones percibidas en lo que llamaré un real primitivo, un real no simbolizado, a pesar de la forma simbólica, en el sentido corriente del término, que adquiere este fenómeno" (Lacan, 2004, p. 97). ¿Cómo entender esta frase? Veamos en qué contexto lo dice.

Lacan está refiriéndose a la fenomenología y a Merleau-Ponty para decir que "la alucinación es integrada como esencial a la intencionalidad del sujeto" (Lacan, 2004, p. 97). Parte de la fenomenología para comentar que aquello que está en la conciencia, es intencional, está en la conciencia, pero no es psicosis.

La alucinación es real, no es psicosis. Más adelante dirá:

Di esa fórmula casi algebraica, casi demasiado transparente, demasiado concreta: lo real o lo que es percibido como tal es lo que resiste absolutamente a la simbolización. A fin de cuentas, ¿no se presenta acaso en su punto máximo el sentimiento de lo real en la ardiente manifestación de una realidad irreal, alucinatoria?. (Lacan, 2004, p. 110).

La realidad puede ser una alucinación y no estar simbolizada, sin embargo, no es psicosis: "Saben ustedes cuán problemático sigue siendo esto, incluso en una psicosis alucinatoria. En la psicosis alucinatoria crónica del adulto hay una síntesis de lo imaginario y lo real; en esto radica el problema de la psicosis" (Lacan, 2004, p. 163). Del mismo modo refiere que en el momento en que una persona escucha que alguien habla y no es así, surge la pregunta “¿Quién habla? Ya que hay 
alucinación, es la realidad la que habla"” (Lacan, 2006a; p. 78). Ahí mismo describe el tema de la señora que viene del fiambrero y escucha que le habla. ¿Qué ha sucedido? La alucinación es algo que se puede percibir, existe y su existencia puede quedar en suspenso, justo como la reducción en la fenomenología: es noema, pero no una irrealidad. En cambio, cuando se percibe que viene de lo real, tenemos que el sujeto se coloca como fuente de la percepción en una indiferenciación con la realidad. Propondrá entonces que en este último caso sí estamos frente a una psicosis en tanto real no simbolizado.

\section{La angustia}

Por el lado que incursionamos podemos apreciar que:

1. La psicosis es la unión de lo real con la alucinación, en su indiferenciación con lo percibido que viene de la realidad.

2. La alucinación puede ser la presencia de algo real pero que no necesariamente llega a quedar fijado así, como el dedo del niño, luego reaparece. La alucinación es temporal.

3. Lo real es perceptible, algo que está ahí y que no es alucinación ni fenómeno psicótico, es algo que ex-siste y emerge: cuando una parte de la realidad es imaginada la otra es real y viceversa.

Con estas frases podemos entrever que el individuo no necesita llegar a lo real, lo real ya lo tiene a él: "La verdad se olvida. Por consiguiente, todo depende de si lo real insiste" (Lacan, 1974a, p. 7). Así, si insiste, podemos inferir que en ello hay algo de lo real a-simbólico que clama por una palabra de otro, para que haga una acción específica, sobre esa imagen, voz o impulso del acto, de modo que se haga la inclusión imaginaria de objetos reales.

\footnotetext{
${ }^{5}$ Esa realidad, devenida como voz que en algún momento fue enunciada por Otro. Es el caso mismo del sueño, en donde emergen ciertas palabras que se escucharon en la vida diurna y que emergen bajo distintos matices enunciativos: a modo del padre comprensivo explicando y calmando, y en otros, como una voz amenazadora o de advertencia.
} 
En La Tercera, editada por Patrick Valas, Lacan muestra el nudo Borromeo (Figura 1) con algunas modificaciones para ilustrar cómo "la invasión del campo de lo real en el campo de lo imaginario produce la angustia en este último campo" (Lacan, 1974b, p. 26).

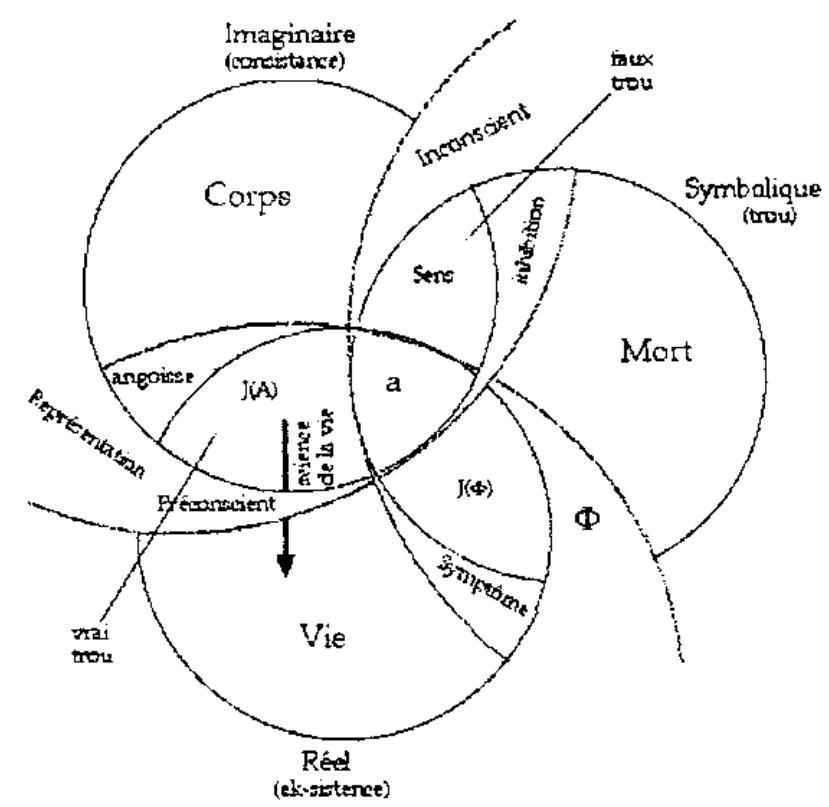

Figura 1: Nudo Borromeo (Lacan, 1974b, p. 26).

Aquí puede verse la interacción entre el cuerpo imaginario, lo real y la angustia, ¿pero de dónde viene ésta última?

La angustia en este entrecruzamiento se presenta como como un signo del acceso a lo real. Lacan siguiendo el concepto de represión de Freud, sostiene que la angustia en las experiencias traumáticas, no se reprime, lo que se reprime es el significante, que Freud denomina representaciones. Lo que regresa enmascarado en los síntomas es una serie de desplazamientos de actos que van acompañadas de un quantum de afecto experimentado en las vivencias traumáticas. Este regreso de lo reprimido en desplazamientos o condensaciones será distinto en los sujetos que quedan devastados, por lo que la angustia aparece desde lo real. 
En el Seminario $X$ refiere la angustia de castración la cual emerge cuando el niño percibe que falta la falta, el deseo de la madre aparece no referida a un tercero, aparece como no barrada por alguien que la separe de la relación dual con el hijo. Está completa a un precio muy alto para el niño: su desaparición como sujeto. El niño queda atrapado al sentirse tomado por la madre como el falo y sometido como objeto único de su deseo.

Para la madre el neonato es algo que puede aparecerle como aspiración de completitud, supone que él es lo que le faltaba -a ella-; es como si operará un discurso inconsciente que consigna: "ese que tiene pene es mío"; por lo que es una manera vicaria e imaginaria de desmentir la realidad. Lo que se podría inferir es que se omite preconscientemente la frase "yo la que tiene nada ahí, no soy la representante del falo".

Pero hay un afecto de parte de él porque cuando ella lo mira, el neonato siente que ese estado dual, fuente del sentimiento de omnitud le da una existencia. El neonato siente que es todo y es aceptado sin alguna consideración ni distancia. Es un momento con luz doble: la completitud de la madre y la completitud del niño. Pero no puede seguir así, ni la madre puede seguir siendo extensión del niño ni éste de ella. ¿Qué sucede? Seguir siendo algo que completa puede ser magnífico para el otro -que se completa- pero es lo más parecido a ser nada para sí mismo. La pretensión de borrar el para sí, mediante un único en sí -el de la madre- es un atentado a la posibilidad del ser. Es ahí que emerge la angustia de castración en el niño, no por el miedo de ser castrado sino de que no llegue ese tercero a castrar- (lo), en la encomienda de la voz del padre: "él no es tuyo, ni ella es tuya". Palabra que efectúa el sentido de la diferencia entre las partes y ordena los lugares genealógicos.

Si esto no sucede, se estanca lo dinámico del ser, el devenir mismo, no hay dialéctica que permita la pregunta ¿qué me quiere el otro? en tanto que, el sujeto queda alienado a un sólo querer, el de la madre. ¿Qué quiere el otro que en ese encuentro lo hace sentir nada? No se puede responder aquello que no se formula a la distancia, pero se vivencia en un proceso que lo desvanece. 
Por lo dicho hasta acá, siguiendo a Lacan, lo real puede generar angustia al menos por tres condiciones: a) porque se enfrenta el individuo a ella sin el velo de las palabras. La exterioridad como tal en su prístino momento del ser le es hostil, no es sino con la libidinización de ese nuevo cuerpo y el apalabramiento de las cosas por parte de los cuidadores que es revestido en su desnudez. b) emerge ante la ausencia de quien le procura los cuidados; lo real amenaza en la ausencia del ser social, genera una sensación de muerte porque es frente al otro que se tiene o no existencia; la construcción del imaginario en la relación del sujeto con sus identificaciones formadoras. Lo real es revestido por la realidad, en un trenzado de imaginario y simbólico; de tal modo que el sujeto al imaginarizar bajo ciertos signos aminora esa angustia. La inclusión del neonato en el lenguaje humano, en la constitución de la ley del lenguaje corre bajo un doble proceso que implica la incorporación de las representaciones cosa y palabra (lo imaginario, lo simbólico) y la capacidad de soportar la presencia/ausencia del otro. Bajo la institución de la ley del lenguaje, el individuo podrá velar lo real con el manto de la realidad-sentido. Finalmente, c) al ingresar en la realidad genealógica, el individuo puede colocarse en el universo de lo social. Y esta se da por la intervención de un tercero que separa al neonato del ser uno con la madre. La no separación de la relación dual hace emerger la angustia de castración; la prohibición del incesto establece la Ley.

Dice Lacan en La Tercera: "Lo real no es el mundo. No hay ninguna esperanza de alcanzar lo real por la representación" (Lacan, 1974a, p. 5), y a continuación pide que se considere la dualidad onda-corpúsculo de la luz, un par de representaciones que son antitéticas pero que ambas explican el fenómeno luminoso. ¿Qué está queriendo decir?

Conjeturamos que la dualidad onda-corpúsculo, se puede entender que en ningún momento podemos ubicar qué es la luz puesto que se presenta de las dos maneras, todo depende del instrumento para captarla. Entonces lo mismo sucede con lo real, en el momento que nos lo representemos como un mundo, estamos alterándolo y habrá cierto espectro que es imposible de incorporar en el campo de la realidad; ya que ese real inaccesible es fuente de todo lo imaginado y simbolizado. Analógicamente, en el campo de la construcción de la subjetividad lo real insiste en los fenómenos residuales, en sus síntomas y resiste la pretensión del discurso del amo que trata de 
obturarla. Este ejemplo ayuda para comprender que en Lacan es diferente la realidad en tanto mundo, preñado de imágenes y sentidos, y lo real. Éste último no es universal, es lo imposible de simbolizar; lo que resiste toda representación por lo que insiste en la repetición del síntoma. Pues a pesar de todos los arreglos o formaciones de compromiso hay un algo irreductible e inaccesible que da consistencia y está coligado con los otros dos registros.

\section{Espejos cóncavos}

En el Seminario I Lacan muestra el diagrama de un espejo frente a otro (Lacan, 2004, p. 191) para distinguir lo imaginario de lo simbólico puesto que uno se refleja en el otro. En este apartado se lee a Lacan desde Zubiri y al filósofo desde Lacan para comprender la forma en que un pensamiento puede abrir interrogantes en el otro.

\section{Zubiri desde Lacan}

En miras de forzar el diálogo entre la propuesta de aprehensión de Zubiri desde Lacan, preguntamos: ¿es suficiente la estructura biológica para que surja la aprehensión primordial de realidad o es necesario la socorrencia los otros más allá del apoyo con la alimentación y el abrigo? ¿La formalidad de realidad es sin mediación? ¿El encuentro entre el aprehensor y lo aprehendido es adecuación tónica "natural" o su inicio es abrumador, pavoroso? Y de ser afirmativa esta última pregunta, ¿ंese encuentro es fuente de dolor y angustia?

Algo importante que la propuesta psicoanalítica ofrece a la descripción de la formalidad de realidad y la aprehensión primordial, es que esta tiene un inicio ontogenético no sólo filogenético. De modo que no se da sin la mediación de un otro que en socorrencia atiende el llamado de un neonato que Ilora. Lacan siguiendo a Freud coincidirá que antes de la cualificación afectiva está el cuerpo que en su primer esfuerzo por existir experimenta displacer por la irrupción de la exterioridad en lo real del cuerpo.

La primera impresión de realidad zubiriana, en Lacan (1974a) puede ser leída desde el Significante primero (S1), el cual se subscribe sin ningún efecto de sentido y que es correlativa esa 
marca al primer objeto de deseo (objeto a). Esta marca de real que deviene por la primera experiencia de satisfacción es el evento inaugural en la constitución de lo éxtimo; proviene desde el mundo de los sentidos y por ser primigenio es modal, es formalidad de realidad, fundamento del posterior mundo de sentidos y del placer. El displacer que emerge aquí puede ser ante una exterioridad que por su fuerza de imposición entra con dolor en lo sentidos. Se infiere además que el aturdimiento del propio llanto, en el neonato es un algo que deviene de afuera, dado que no hay discriminación entre yo y lo otro, no hay todavía un afecto como el temor por algo concreto sino dolor-angustia por la incapacidad de imaginarizar y simbolizar ese mundo caótico. En este punto, la propuesta psicoanalítica coincidiendo con Heidegger (1993) sostiene que, esta angustia emerge ante la falta de significatividad. Si pensamos al fenomenólogo con el hallazgo psicoanalítico se diría que el neonato, "no es nada, no está en ninguna parte", pero la exterioridad como tal es abrumadora y pavorosa. Y en el brote psicótico además es desazón y extrañamiento de lo familiar, en tanto que el sujeto por un lado queda como aislado de lo cotidiano en solipsismo, y por otro, pavorosamente queda abrumado por la pérdida de independencia con el Uno originario. La pérdida de la diferencia e independencia con el Uno, dicho bajo las conjeturas psicoanalíticas significa que en un primer momento el soporte existencial del niño es la imagen de la madre. Esta imagen ordena el mundo caótico, pero es endeble, porque aparece y desaparece del campo perceptivo. Y gracias a su repetición termina siendo una imagen que se guarda; en ella podríamos sostener el primer quedar en impresión. Este primer encuentro podría ser considerado la fuente de toda actualización de lo real, la formalidad de la realidad en tanto otro humano que se me impone como siendo en propio, y cuya fuerza de imposición es correlativa a la constancia de la presencia como al modo de quedar en impresión por la índole misma del animal humano. Ese otro en tanto imagen que sostiene, tiene un poder que trasciende un contenido, ya que hay una variedad de atributos y funciones posibles; además ese otro es Uno y tras ese uno, hay más (es el más como momento del "de suyo") ${ }^{6}$. La respectividad de la formalidad de realidad y de la aprehensión primordial en Zubiri es sostenible como explicación que pretende decir cuál es la talidad de lo real y de la aprehensión

\footnotetext{
6 Heidegger sostiene: soy los otros a la manera del Uno.
} 
humana. Propuesta a la cual agregamos el énfasis psicoanalítico de que la modalización de ésta pende de una cosa en tanto imagen humana que media y modela la formalidad de realidad. Por lo que la terna zubiriana: afecto, la alteridad y la fuerza de imposición en tanto impresión de realidad,

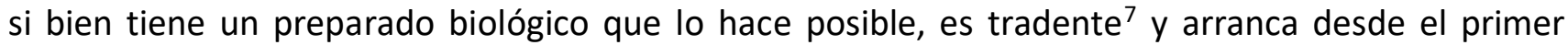
contacto del neonato con la exterioridad la cual está mediada por el otro como auxiliar.

Un segundo elemento a considerar, y que es articulable entre las propuestas, es que la impresión de realidad implica un afecto, una alteridad de lo otro como en propio y una fuerza del "estar ahí" que imprime su poder al percipiente. La acotación a la propuesta zubiriana desde el psicoanálisis, es que esto no es, sin un trayecto ontogenético, que va de la mediación de las propias tensiones corpóreas, así como de la in-corporación de la exterioridad, a la representación cosa a la representación palabra. Pero esto sólo es posible si admitimos que hay una modalización, fundamental, una huella mnémica, un Significante primero (S1), una impresión modal que queda como formalidad de realidad en impresión de realidad y que es lo propio de la habitud humana, en tanto que el S1 es correlativo al objeto causa de deseo.

Un tercer punto es que ese quedar primario como S1, como impresión de lo otro es un irreductible simbólico que aún en los estados de desestructuración psicótica está. Dado que la impresión primordial está referida al auxiliar y usualmente es la madre quien nutre e inserta al neonato en el mundo de lo humano. Esta inserción para el psicoanálisis no es inocua, y de acuerdo con Heidegger (1993) es en esa primera vehiculización que "Encontrarse ${ }^{8}$ y comprender son determinados... por el habla" (p. 150). La disposición afectiva que el psicoanálisis atribuye al niño y a la madre en ese encuentro es de completitud existencial, en el orden imaginario. Si bien el neonato irá cualificando el sentir hasta lograr expresarlo en afectos, el sentido de omnitud es especular en tanto se sostiene en la imagen de grandiosidad que el niño ve reflejada de su proveedor (a). El sentido existencial, la afirmación especular inicial es dada por el otro, pero no es sino por el desasimiento de ese otro que el sujeto logra la distancia e independencia, de ese "de suyo"

\footnotetext{
${ }^{7}$ Lo tradente, es referido por Zubiri como aquello que nos es dado por las pautas culturales y sociales, allende la biología.

${ }^{8}$ En otras traducciones se lee: disposición afectiva.
} 
formador. Así, el psicoanálisis, al problema noológico del filósofo le agrega que la alteridad no es, sin un trans-citar, de la relación dual del encuentro hacia un ternario que posibilita la diferencia y la separación del Uno primario. Por lo que, la madre tendrá que renunciar al sentir omnipotente que le da la imagen de "ser creador que engendra". Este quiebre es frágil ya que el sentido de existencia pende de la imagen, pero si no hay un deshacimiento de ella quedarían atenidos a la ilusión del sí mismo como otro; en una relación dual. La pérdida en la separación es la fuente del placer de la carencia de lo amado, pero ya no presente sino por el recuerdo ${ }^{9}$.

Así pues, lo a-simbólico de la primera impresión y la no separación del primer objeto de amor, pueden ser angustiantes. Ser nada ${ }^{10}$, ese es el origen de la angustia, la nada que enfrenta el neonato ante una cosa-madre que a la vez que le ofrece una imagen que le da continuidad es condición de pérdida, por lo que está imagen del ser, es endeble, pues si no hay pérdida por la separación queda en entredicho el me-mí, en tanto sí mismo del sujeto.

En la Figura 1, puede apreciarse que el punto de conjunción entre el círculo imaginario y el círculo de lo simbólico es el sentido (sens), aquí está la realidad, no lo real, sino la realidad mundo para el sujeto. Una realidad mundo imaginaria hecha para sobrevivir en existencia, que le permita colocar un velo, un revestimiento a la angustia.

Para Lacan el niño se enfrenta a la angustia y utiliza el lenguaje para velarla. Además, crea el sentido que le permitirá una existencia genealógica, gracias a la intervención de un tercero que marca la separación y diferencia. Sin embargo, en algunos momentos de la vida del sujeto, ese velo se rasga y entonces lo real queda en indiferenciación con la realidad, y emergerá la angustia.

El logos es para con-tener la verdad de las cosas, pero no la verdad real; la verdad real es la posibilidad de la verdad dual, de la cosa sentido. La verdad dual indica un saber sobre qué es el objeto al cual nos enfrentamos entre otros objetos. La verdad hace referencia a las cosas, no

\footnotetext{
${ }^{9}$ Lacan expone: ... "la madre [...] es el primer objeto simbolizado, y su ausencia o su presencia se convertirá para el sujeto en el signo del deseo al que se aferrará su propio deseo, y que hará o no de él, no simplemente un niño satisfecho o no, sino un niño deseado o no deseado" (Lacan, 2005. p. 265).

${ }^{10}$ La angustia ante la nada puede leerse desde el psicoanálisis, como el enfrentamiento a lo no simbolizado de ese real en tanto exterioridad, en tanto complejo de objeto o del prójimo, y/o como eso que emerge no sólo porque falsea la ley del lenguaje, sino porque la Ley del padre en tanto regulador del goce de la madre no llega.
} 
podemos vivir sin saber qué es ella, no sabríamos a qué atenernos. Es la función del lenguaje mostrarnos la verdad de la cosa, actualizada entre otras.

El neonato llega al mundo con el cuerpo sin control, fragmentado dice Lacan en la teoría del espejo. Se debe aprender a controlar el cuerpo y para eso es necesaria la imagen de alguien que ya atravesó el proceso y realiza la acción específica que responda a su llamado. El cuerpo es algo construido como instrumento perceptual y sobre todo de goce, el estudio de la psicosomática lo atestigua; Zubiri no aborda este aspecto porque parte de que, por la hiperformalización todos los humanos aprehendemos realidad, sin embargo, cabe la pregunta de si el mismo de suyo no es derivado de la integración de la corporalidad, en cuyo caso habría algunos sujetos que al aprehender la realidad fallan. Estamos hablando de una genealogía de la corporalidad no sólo pensante sino gozante y, por ende, del animal de realidad y de deseo.

\section{Lacan desde Zubiri}

Zubiri permite leer a Lacan en el tema de la alucinación y el de la angustia. Al primer término aportará que es cierto, alguien puede alucinar, pero no significa que sea real, aunque sí exista. Del segundo podrá decirse que la angustia aunque sea tan valorada por el movimiento existencialista y por Heidegger (Zubiri, 1992), el afecto de sentir angustia no es lo radical, lo radical es la formalidad de lo real -su arkhé ${ }^{11}$ - Ese devenir que tiene su fuente de poder en la naturaleza en tanto actúa sobre sí y sobre los otros.

Para Zubiri, se ha logrado aprehender la realidad como realidad y tiene la posibilidad de concebir algo que no existe pero que tiene efectos, es la realidad re-actualizada que puede adoptar la forma de percepto, ficto y concepto, re-actualizaciones de lo real que brindan la posibilidad de que el sujeto pueda tener una ilusión o una alucinación.

Siguiendo a Lacan con Zubiri, la realidad reactualizada bajo la forma del espectro -cosa sentido- en el sujeto puede velar lo real mitigando el efecto de imposición que las cosas tienen y que genera lo que Lacan llama angustia. Puesto que la ilusión de las cosas que existen y no son de

\footnotetext{
${ }^{11}$ Ver la nota 1.
} 
suyo, tienen la capacidad de velar, el niño mantiene una realidad ilusa ante la imposición de las cosas. En palabras de Lacan, logra mantener la angustia lejos y en algunos momentos, lo real se apodera del sujeto porque rompe el velo de la realidad-mundo imaginario y que Zubiri llama espectro.

¿De dónde proviene la angustia en Lacan? Es un derivado de estar ante lo real asimbólico como ante la amenaza de no castración. Mientras que para Zubiri lo radical es lo poderoso de lo real en tanto fuerza de imposición que se impone con su dureza al humano. Lo real se impone con su propia fuerza de forma independiente a cómo lo quiera definir el humano. La formalidad de realidad apunta al un-factum.

Con la aprehensión primordial el niño ha quedado en la realidad y su poderosidad, pero ahí no termina todo porque, aunque esté en lo real, todavía no sabe qué son las cosas reales en la realidad a fin de manejarse entre ellas y poder estar en sociedad. Y para saber qué es cada cosa entre las demás cosas que aprehende y qué son las cosas allende su aprehensión, es decir, necesita continuar con la marcha de la inteligencia actuando en las otras dimensiones del ser.

Lo poderoso bien puede generar angustia, por algo el pensamiento animista le atribuyó esa fuerza divina, pero esto sería en Zubiri secundario pues lo radical del sentir es ge tivo, es sentimiento de realidad, y como tal, es el individuo queda atemperado a la realidad aprehendida de una cierta manera. Lo poderoso exige la marcha de la inteligencia para ubicar al sujeto en la realidad.

La realidad tiene tres rasgos como formalidad: ser de suyo, fuerza y poder que Zubiri vincula al planteamiento de Anaximandro, "lo indeterminado": lo que no tiene límites y es fuente de todo, lo ápeiron, el arké. Todo neonato se enfrenta a esto una vez que llega al mundo, tiene una sensación ante lo indeterminado que se apodera de él. Que se apodere de él y que sea indeterminado es el enfrentamiento del neonato al auxiliar, es el enfrentamiento de un yo real instintivo a un real de la cosa que se le mete en el cuerpo. Podemos inferir que el neonato ante el poder de lo real y su sensación de fragilidad, siente angustia; también podemos conjeturar que como seres humanos ante la vida y sus diferentes facetas buscamos darle un sentido y podemos 
percibir la fragilidad de los sentidos que imaginamos para enfrentar la vida; la posibilidad de la caída y el fracaso de éstos, provoca angustia.

He aquí que lo real como oquedad de sentido lleva al individuo social a enfrentar su propia vacuidad y como reacción, a buscar perceptos, fictos y conceptos -en palabras de Zubiri- o explicaciones -en términos comunes- que le permitan continuar su vida.

Zubiri expone que la angustia como discusión intelectual se puso de moda en el siglo XX porque Heidegger planteó que la angustia es un camino para responder la pregunta por el ser:

El hombre está apoyado en la vida en los entes que le rodean (das Seiende). Su hundimiento total deja patente ante los ojos de aquél la nada de todo ente. Este vacío es en sí mismo algo positivo: es el "ser" (das Sein). Sobre el abismo de los entes queda flotando el puro ser. A fuer de tal, la angustia es para Heidegger un fenómeno ontológico, es la patentización del puro ser a diferencia del ente. (Zubiri, 1992, p. 396).

Si partimos de Lacan, el niño en algún momento está ante algo real, algo que tiene efectos y que lo enfrenta con los registros imaginario y simbólico para crear un velo que le permita cubrir la angustia. Zubiri llama hiperformalización a la puesta de la realidad ante el sujeto, pero no teoriza que el de suyo sea puesto por él, sino desde la perspectiva del proceso de la evolución humana ${ }^{12}$.

\section{Conclusión}

Al final del recorrido los conceptos se mezclan, es así que podemos decir que como humanos nos enfrentamos algo real que se impone con rasgos de poder, fuerza y épyov, y ante la cual no sabemos qué esperar: en ese momento surge la angustia. Aparecida ésta, buscamos el camino para eludirla y lo encontramos en el velo de las imágenes y palabras preñadas de sentido: la realidad; con

\footnotetext{
12 Es importante advertir que Zubiri no es ingenuo. La capacidad existe, pero esta no es, si no se desarrolla. En su tratado Sobre el hombre lo aborda, al hablar de la dimensión social. Es decir, el sujeto sí viene con ciertas "disposiciones" genéticas y acorde a las antropologías de la época asume que hay cierta competencia heredada que se desarrolla. Esto lo aborda Freud, y dirá de ello "esquemas filogenéticos". En esto confluyen Zubiri y Freud.

Los estructuralistas toman distancia sobre este principio, no porque sean ingenuos sino para interrogar a toda ciencia positiva, en tanto que, lo que digamos sobre las cargas genéticas no es sino en el campo del lenguaje de la época.
} 
esta jugada el sujeto queda amparado ante la imposición de un exterior disruptivo. Sin embargo, el poder de lo real ahí está y en algún momento volverá, justo para rasgar el velo del sentido y dejarnos entrever en su insistencia la oquedad del ser, algo real de suyo poderoso.

Para Lacan la angustia es lo que no engaña, es lo que emerge ante lo real; no engaña porque la angustia desgarra cualquier vestidura del sentido, de esa realidad que han tejido las palabras. Cualquier otra afectación tiene la potencia para convertirse en sentido y seguir velando la realidad. Para Lacan no hay forma de no pasar por la angustia; podemos decir que, si queremos llegar al Tebas de lo real, es necesario enfrentar la mirada de la Esfinge, pero eso angustia.

Para finalizar se ofrecen las siguientes conclusiones de este diálogo:

La primera es que la formalidad de realidad en impresión, no sólo es filogenética (Zubiri), sino que implica un trayecto ontológico en el lenguaje, en un ser que inicialmente es niño.

La segunda es a propósito del tema de la angustia. Se ha discurrido aquí que el encuentro entre el percipiente y la fuerza y poderío de lo real es en respectividad, pero la incorporación de la nuda realidad impacta porque en el arranque de ese encuentro el cuerpo experimenta dolor y estímulos no específicos de lo real que abruma y apabulla al percipiente, por lo que es admisible que eso lo podríamos entender como angustia. En Lacan, si el efecto de lo real en el animal humano es dolor y angustia, hay un traumatismo en la experiencia primera cuando se da el enfrentamiento con lo real. En Zubiri la impresión de realidad implica afecto, alteridad y fuerza de imposición y tiene su correlato con la formalidad de realidad, como siendo de suyo y dominando sobre el contenido. Este relato entre la formalidad de realidad y la impresión de realidad es en respectividad por lo que el animal de realidad se ajusta afectivamente atemperándose al mundo. Por lo que, el primer sentir es afectación de la realidad a la que se atempera, sobre ese en propio del sentir como de suyo. En ese sentimiento se cualificarán los contenidos afectivos de angustia, tristeza etc. Por lo dicho aquí, podemos concluir que las posiciones no son excluyentes, pues, aunque la primera experiencia del neonato con lo real pueda ser disruptiva, después hay un ajustamiento a ella mediada por el auxiliar. Y aún en la desestructuración psicótica la angustia es temporal, y quizá la acción específica 
de los otros, permite ir cualificando la distancia de lo real de la cosa ayudando con el apalabramiento y la cualificación del sentir.

Tercero, Zubiri propone que la aprehensión primordial de realidad es la fuente de todo saber pensado posteriormente por el logos y la razón. En Lacan y Freud, hay un antes de esa impresión formal de realidad, esto es la exterioridad como indiscriminación, como caos. Por lo que sólo por el sentir humano es que adquiere sentidos la formalidad de lo real. En lenguaje zubiriano, la Respectividad de lo real (1976-1979) sólo es saber humano por el logos y la razón, y sin ese en re primero de la formalidad de realidad, no hay posibilidad del sentido.

En esto último punto podemos vislumbrar una coincidencia entre Lacan y Zubiri, a saber: que lo real es el tendido frente al cual se articulan el imaginario y simbólico en el psicoanalista, mientras que, para el filósofo, es el principio formal sobre el cual avanza la marcha intelectiva del logos y la razón.

Cuarto, para Zubiri la formalidad de realidad y la impresión de realidad orbita alrededor de inteligir el de suyo de la cosa vía la alteridad y reconociendo el poderío trascedente. El de suyo como principio de alteridad es lo propio del animal de realidades y en la propuesta del filósofo pareciera que es algo dado por las estructuras de hiperformalización. Para el psicoanalista la independencia, distancia y diferenciación es precisamente el quid, lo cual no se da sin la lengua vía el otro, que permite imaginarizar y entender-se en un mundo de realidades y genealogías.

Finalmente, por el poderío de lo real que se impone como siendo de suyo es que la alteridad es un trayecto; el hombre trasciende en ella lleno de sentidos con o sin angustia. Zubiri emparenta la poderosidad con el arkhé de Anaximandro y lo conducirá a filosofar. Lacan enfrenta lo real que se impone con toda su fuerza mediante la retórica, pues por su práctica sabe que es mediante el habla que se puede apalabrar lo pavoroso. Y reconoce que, bordeamos la cosa con palabras y es en la imposibilidad de imaginarizarlo y simbolizarlo todo que es factible lo real (Lacan, 1974a). Así mismo, las marcas auditivas devenidas de fuera (representación palabra) imperan el hacer, en ocasiones fuera de todo lo imaginado y declarativamente admisible; es la función del deber que cual dios o voz del destino impele sacrificio y muerte. Así la fuerza de la realidad y su poderío en lenguaje 
zubiriano no es, hablando desde Lacan, sino por las voces imperantes de las imagos primeras que dominan el ser y hacer del sujeto. Estas voces tienen fuerza de imposición y dureza como una piedra que nos cae en la cabeza, pues no sólo es exterioridad-cosa que se me impone sino además es palabra-comando que dicta un destino.

Queda pendiente discurrir en otro escrito, como la fuerza y poderosidad de lo real son los emblemas del falo en la sociedad patriarcal. Para lo cual tendríamos que hacer dialogar el espectro zubiriano y el fantasma lacaniano.

\section{Referencias}

Aristóteles. (1994). Metafísica. Madrid, España: Gredos.

Gracia, D. (2016). Teoría del espectro. The Xavier Zubiri Review, XIV, 95-111.

Heidegger, M. (1993). El Ser y el tiempo. Barcelona, España: Planeta-Agostini.

Lacan, J. (16 de Enero de 1963). Seminario X: La angustia, Clase 8. Obtenido de Lacantera Freudiana: https://www.lacanterafreudiana.com.ar/2.1.4.8\%20CLASE-08\%20\%20S10.pdf

Lacan, J. (1 de Noviembre de 1974a). La Tercera. Ed. La escuela Freudiana). Obtenido de La cantera freudiana: https://www.lacanterafreudiana.com.ar/2.5.1.35\%20\%20LA\%20TERCERA.pdf

Lacan, J. (1 de Noviembre de 1974b). La Tercera. Ed. P. Valas. Obtenido de Psico: http://88.27.249.81/psico/sesion/ficheros_publico/descargaficheros.php?opcion=textos\&codigo $=334$.

Lacan, J. (2004). Seminario I: Los escritos técnicos de Freud. Buenos Aires, Argentina: Paidós.

Lacan, J. (2005). Seminario V: Las formaciones del inconsciente 1957-1958. Buenos Aires, Argentina: Paidós.

Lacan, J. (2006a). Seminario III: Las psicosis. Buenos Aires, Argentina: Paidós.

Lacan, J. (2006b). Seminario X: La angustia. Buenos Aires, Argentina: Paidós.

Merleau-Ponty, M. (1994). La fenomenología de la percepción. España: Planeta-Agostini.

Nietzsche, F. (1986). Humano demasiado Humano. México: Editores Mexicanos Unidos.

Nietzsche, F. (1990). Sobre verdad y mentira en sentido extramoral. Recuperado de: http://www.lacavernadeplaton.com/articulosbis/verdadymentira.pdf 
Nietzsche, F. (2000). Voluntad de poder. Madrid, España: Biblioteca Edaf.

Sartre, J. (2006). El ser y la nada. Buenos Aires, Argentina: Lozada.

Zubiri, X. (1962). Sobre la esencia. Madrid, España: Alianza.

Zubiri, X. (1976-1979). Respectividad de lo real. Realitas III-IV, IV, 13-43.

Zubiri, X. (1980). Inteligencia sentiente. Madrid, España: Alianza.

Zubiri, X. (1982). Inteligencia y logos. Madrid, España: Alianza.

Zubiri, X. (1983). Inteligencia y razón. Madrid, España: Alianza.

Zubiri, X. (1987). Sócrates y la sabiduría griega. Naturaleza, Historia y Dios. Madrid, España: Alianza.

Zubiri, X. (1992). Sobre el sentimiento y la volición. Madrid, España: Alianza.

Zubiri, X. (2005). El hombre: lo real y lo irreal. Madrid, España: Alianza. 